\title{
IMAGINARIOS ESPACIALES DEL SUR EN LA POESÍA DE JAIME HUENÚN E IVONNE COÑUECAR ${ }^{1}$.
}

\section{SOUTH SPACE IMAGINARS IN JAIME HUENÚN E IVONNE COÑUECAR POETRY}

\author{
Samir Said Soto \\ Universidad de Playa Ancha de Ciencias de la Educación, \\ Valparaíso, Chile \\ Dr.@ en Literatura Hispanoamericana Contemporánea, \\ ssaidsoto@gmail.com
}

\begin{abstract}
Resumen:
El objetivo de este artículo es identificar cuáles serían los imaginarios espaciales más relevantes que se manifiestan en la poética de Jaime Huenún e Ivonne Coñuecar. Al respecto, se plantea, como hipótesis, que las producciones escriturales de ambos autores son originadas a partir de un locus geográfico de enunciación específico, en el que se manifiestan una serie de representaciones simbólicas espaciales que estarían en tensión con el imaginario social instituyente de la nación. Frente a esas representaciones, concebidas como imaginarios espaciales del sur y como una interrelación compleja entre experiencia, espacio e imaginario, los/as sujetos poéticos/as de ambos autores se presentan como subjetividades en conflicto.
\end{abstract}

Palabras clave: Poesía mapuche; sur; imaginarios; espacio; experiencia.

\begin{abstract}
:
The objective of this article is to identify which would be the most relevant spatial imaginaries manifested in the poetry of Jaime Huenún and Ivonne Coñuecar. In this regard, it is suggested, as a hypothesis, that the scriptural productions of both authors are originated from a geographical locus of specific enunciation, in which a series of spatial symbolic representations are manifested that would be in tension with the instituting social imaginary of the nation. Faced with these representations, conceived as spatial imaginaries of the South and as a complex interrelation between experience, space and imagination, the poetic subjects of both authors present themselves as conflicting subjectivities..
\end{abstract}

Keywords: Mapuche poetry; south; imaginary; space; experience.

Recibido: 28 de octubre de 2019

Aceptado: 10 de diciembre de 2019

\footnotetext{
${ }^{1}$ Este trabajo forma parte de mi Tesis de Doctorado de la Universidad de Playa Ancha de Ciencias de la Educación. "Imaginarios espaciales del sur en la poesía de Jaime Huenún e Ivonne Coñuecar", la que se enmarca dentro del Proyecto FONDECYT-Iniciación Nº 11150141 de la Dra. Fernanda Moraga-García.
} 


\section{Consideraciones preliminares.}

En la mayor parte de la poesía de autores y autoras mapuche el espacio se muestra como un elemento semántico que posibilita múltiples lecturas y relaciones con otras áreas de significación que involucran subjetividades en conflicto. De este modo, nos parece relevante explorar la relación entre espacialidad, experiencia e imaginarios a partir de una propuesta de lectura de la poética de dos autores: Jaime Huenún (1967) e Ivonne Coñuecar (1980). En ambas producciones, la relación de estas temáticas se presenta como una problemática territorial que se traduce en imaginarios espaciales del sur y en los cuales es posible identificar sujetos poéticos/as en tensión.

Si nos aproximamos a los contextos que enmarcan los proyectos escriturales de Huenún y Coñuecar, es recurrente en su poesía la configuración de espacios del sur, los que dan cuenta de una historia hegemónica que ha desconocido las diversas versiones derivadas de sus "memorias culturales" (Mansilla 2015). Esta historia es la que produce y ha producido una neutralización no solamente cultural, sino también política e identitaria sobre la sociedad mapuche. En relación a la idea de "memorias culturales", ésta ha sido trabajada por autores como Benjamin (1932), Hallbwachs (1950), entre otros. En el contexto nacional, y en relación a la poesía mapuche, la idea ha sido utilizada por James Park (2010) y Sergio Mansilla (2015). Para el caso de nuestro trabajo, nos adscribimos a la perspectiva de Mansilla, quien, al analizar el contexto socio-histórico mapuche, asume que la heterogeneidad cultural producida en espacialidades como las ciudades, a partir de la interrelación entre el mestizaje, la indecibilidad identitaria, y los trazos de la memoria, es un elemento que permite hablar de "memorias culturales" que, en algunas ocasiones, intentan manifestarse a través del discurso poético con la finalidad de descolonizar el devenir histórico (2015: 162).

Desde este punto de vista, en la producción poética de Huenún y Coñuecar, la representación de los imaginarios espaciales del sur es un referente importante dentro de la poesía mapuche actual, puesto que en ella es posible entender el espacio no como un simple marco físico o geográfico donde se localizan objetos o cosas, sino como un sistema de espacialidades (Stavrides 2016) en el cual la complejidad de la experiencia es ineludible. Con esto, queremos decir que en este sistema se movilizan significaciones, conocimientos y controles relacionados a las transformaciones $\mathrm{y}$ dinámicas de poder que en esos espacios se dan, ya sea como lugares de encuentros, intercambios, choques o luchas, pues tal como señala Stavrides: "Las distintas formas de 
definir y controlar el espacio son construcciones espaciales, y como tales no sólo reflejan distintas relaciones sociales y valores sino que los moldean e intervienen en la construcción a su vez de experiencias concretas, socialmente significativas.” (20).

Si relacionamos la idea de Stavrides con el locus de enunciación que Huenún y Coñuecar proponen, podemos entender que ambos resignifican el sentido de los imaginarios espaciales del sur mediante el discurso de sujetos poéticos que reclaman el lugar de una subjetividad inserta en un contexto epistémico y social que le es contradictorio. En gran parte de la obra de estos autores, la subjetividad es representada por las voces poéticas de sujetos mestizos/as mapuche ${ }^{2}$ que ahondan en problemáticas que difieren dentro de la construcción del espacio y en la producción de la experiencia.

La poesía de estos escritores adquiere un lugar que critica al homogéneo discurso de la historia chilena, siendo la configuración de las espacialidades un punto de fuga que permite plantear, a modo de discusión y contradiscurso, poéticas que abren la posibilidad de situar y entender los diversos imaginarios espaciales del sur. Como ya se ha explicado, el presente artículo se propone indagar en algunos -quizás los mas relevantes a nuestro juicio- de los imaginarios espaciales del sur representados en gran parte de la poesía de Huenún y Coñuecar.

Con la finalidad de comprender el espacio simbólico que transita en la producción de estos poetas, se entenderá la idea de sur a partir del concepto de "suralidad", es decir, como:

\footnotetext{
${ }^{2}$ Es pertinente señalar que nuestro corpus de investigación presenta en su discurso la complejidad de un/a sujeto que se asume como mestizo, por tanto, se entenderá la noción de mestizaje a partir de la propuesta teórica de Francois Laplantine y Alexis Nouss, quienes señalan que "El mestizaje es un pensamiento -y ante todo una experiencia- de la desapropiación, de la ausencia y la incertidumbre que pueden surgir de un encuentro." (2007: 1). En esta relación conflictiva entre experiencia y espacio, desde la que se desprende un pensamiento mestizo, el sujeto se repliega y despliega frente a lo que estabiliza, identifica y categoriza de manera totalizante. En sintonía con la idea que propone Bhabha (1994) sobre el "tercer espacio" como lugar fronterizo en el cual no es posible reducir ni la identidad ni la diferencia, y a partir de una tercera vía entre lo homogéneo y lo heterogéneo, Laplantine y Nouss nos permiten plantear también que gran parte de la poesía de Huenún y Coñuecar simboliza, entre otras complejidades, esta espacialidad de la alteridad en el que las voces poéticas son la representación de sujetos mestizos/as mapuche.

${ }^{3}$ Este concepto es desarrollado por Claudia Arellano y Clemente Riedemann en el libro Suralidad. Antropología Poética del Sur de Chile (2012), en el cual se establecen relaciones entre las percepciones de "Sur" e "Identidad", integrando las categorías de territorio e imaginario a partir del análisis de producciones poéticas de autores del sur de Chile como Delia Domínguez (1931), Jaime Huenún (1967), Rosabetty Muñoz (1960), Yanko González (1971), Juan Paulo Huirimilla (1973) y Roxana Miranda Rupailaf (1982), entre otros. Arellano y Riedemann consideran la idea de "suralidad", en un sentido amplio, como la producción cultural desde el Cono Sur (Sudamérica), y en un sentido más acotado, como la producción cultural desde el sur de Chile. Según esta apreciación, entendemos que ambos enfoques reconocen espacialidades que se perciben a si mismas desde el otro polo de los centros de control cultural.
} 
[...] un conjunto de rasgos de identidad observables en el espacio y la temporalidad histórica denominada "sur de Chile", cuyas fronteras son percibidas simbólica o concretamente; un territorio signado por cruces étnicos, culturales, históricos, tecnológicos y lingüísticos en permanente reconstrucción o resignificación (13) [...] donde la producción poética es un fenómeno con suficiente capacidad explicativa para establecer elementos de pertenencia, identidad y diferenciación en el sistema nacional de las comunicaciones literarias [...] (Arellano y Riedemann 2012: 35).

Esta suralidad, concebida como un constructo de manifestaciones espaciales y experienciales, tiene una estrecha relación con la producción de significaciones simbólicas. Para comprender esta dinámica dialéctica entre imaginarios y espacialidades a partir de la poesía de nuestros dos autores, se propone como perspectiva de análisis la idea de "imaginario social instituido", de Cornelius Castoriadis:

\begin{abstract}
¿De qué manera detallar esta obra del imaginario social instituyente? Consiste, por una parte, en las instituciones. Pero la consideración de estas instituciones muestra que están animadas por $-\mathrm{o}$ son portadoras de-significaciones que no se refieren ni a la realidad ni a la lógica: por ese motivo las llamo significaciones imaginarias sociales [...] Una vez creadas, tanto las significaciones imaginarias sociales como las instituciones se cristalizan o se solidifican, y es lo que llamo el imaginario social instituido. Este último asegura la continuidad de la sociedad, la reproducción y la repetición de las mismas formas, que de ahora en más regulan la vida de los hombres y permanecen allí hasta que un cambio histórico lento o una nueva creación masiva venga a modificarlas o a reemplazarlas radicalmente por otras formas (2006: 4).
\end{abstract}

Entenderemos los imaginarios del sur, entonces, a partir de su institución como convenciones implícitas de un colectivo social, los que, además, tienen un carácter dinámico, incompleto y móvil. De esta manera, su poder para operar en las acciones de las personas desde procedimientos sociales, los constituyen en elementos de cooperación en la interpretación de la realidad social. En este sentido, y en relación a lo propuesto por Castoriadis, resulta importante considerar que Huenún y Coñuecar elaboran voces poéticas que representan a subjetividades mestizas y proponen una mirada crítica en contraposición a los imaginarios colonialistas. Desde este complejo espacio enunciativo del/la "yo" poético/a, podemos presenciar la manifestación de imaginarios topolésbicos inscritos en la espacialidad de la Patagonia, en el caso de la 
poesía de Coñuecar; o la manifestación de imaginarios sociales mapuche, en los que las espacialidades son representadas como "espurias patrias", en el caso de la poesía de Huenún.

\section{Imaginarios espaciales del sur en la poética de Jaime Huenún.}

Jaime Huenún ha publicado cinco libros de poemas: Ceremonias (1999), Puerto Trakl (2001), Reducciones (2013), Fanon City Meu (2015), y La calle Mandelstam y otros territorios apócrifos (2016). Por otro lado, ha sido editor de antologías como: Epu Mari Ülkantufe ta fachantü. 20 Poetas Mapuche Contemporáneos (2003), La memoria iluminada: Poesía Mapuche Contemporánea (2007), y Los cantos ocultos. Antología de Poesía Indígena Latinoamericana (2008).

Huenún se ha centrado principalmente en visibilizar la degradación y pérdida de la memoria cultural mapuche-huilliche, debido a la imposición colonial en el siglo XVI y a partir de la cual se han forjado una serie de reducciones territoriales que se concretan en el periodo de la República en el siglo XIX y que con diferentes enmascaramientos, perduran hasta hoy. En el proceso colonialista que va desde el siglo XVI hasta comienzos del siglo XX, podemos mencionar el "Tratado de las Canoas" (en Chaurakawin, Osorno, en 1793), las misiones religiosas permanentes a partir de la segunda mitad del siglo XVIII y la colonización alemana y chilena desde mediados del siglo XIX. En esta última etapa, se suma la mal llamada "Pacificación de la Araucanía": “Así era, mamita, así fue:/ las estrellas dejaron de alumbrarnos/ la sangre de repente,/ y tuvimos que ocultarnos como zorros/ en montañas y barrancos." (Huenún 2012:105) ${ }^{4}$. Estas transgresiones violentas, revisadas y analizadas en diversos estudios (Marimán y otros 2006; Cárcamo-Huechante 2007; Nahuelpán y otros 2012; Canales 2016, entre varios más), hablan de la violenta penetración occidental en el territorio mapuche, situación que incide en la mayor parte de la poesía del autor. Por ejemplo, leamos estos versos: "Las ciudades son ahora el final de tu memoria,/ la escritura humedecida de tus sueños siempre nómadas./ Es por ello que no olvidas una plaza, una explanada/ donde el pueblo erige a tumbos una gris catedral.” (50).

La obra de Huenún se instala en el corpus literario mapuche-huilliche a través de una propuesta que ironiza frente al discurso historiográfico oficial. Desde esa ironía se origina un yo poético que podría ser representativo de una pluralidad de subjetividades

\footnotetext{
${ }^{4}$ Desde aquí en adelante se trabajará con diferentes poemarios de Jaime Huenún, y las citas de los versos se distinguirán por el año de publicación que se referencia en cada una de ellas.
} 
conflictuadas a partir de la relación de poder que ejerce sobre ellas la hegemonía colonial. Esta relación, en gran parte de su poesía estaría concretamente situada en el espacio-sur de Chile: "De lejos los vi, hija, de lejos lo sabía./ Grande fue mi sueño, mi revelación:/ blanquito amanecía el cielo de Forrahue/ con dos caballos negros garañones/ pateándose allá arriba.” (109). Como se mencionó anteriormente, la ironía puede verse en la mayor parte de la poesía del autor, a partir, por ejemplo, de la apropiación de recursos discursivos y estilísticos provenientes del mundo científico occidental, o en la utilización de citas de textos periodísticos o antropológicos y documentos policiales (Huenún 2012) y a través de los cuales el sujeto poético asume la voz de quien los emite, es decir, del colonizador. La finalidad de esta estrategia, es resignificar metafóricamente estos documentos para dar cuenta de los distintos tipos de violencia ejercida sobre los mapuche: "Quedaron muertos once indígenas (5 hombres y 6 mujeres), ocho heridos, de los cuales han fallecido cuatro en el hospital. De los carabineros y policía quedaron heridos siete, entre ellos el sargento $1^{\circ}$ Arias, con un balazo en el abdomen y heridas de mucha gravedad en la cabeza (informe médico, fjs. 144)." (103); "HE DISECADO MUCHOS CADÁVERES/ Y NUNCA HE ENCONTRADO UN ALMA" $(73)^{5}$.

En los poemarios de Huenún, esta polifonía se construye a través de los ecos del pasado y del presente de una comunidad que logra verse a sí misma a partir de construcciones imaginarias que, en el devenir entre lo político y lo social, la marginan y estereotipan.

A partir de esta posición crítica, la poesía de Huenún alegoriza algunas de las diferentes voces excluidas en el discurso de la historia nacional y latinoamericana. La postura crítica que apropia el poeta en sus textos y el ejercicio recurrente de evidenciar la violencia y la degradación ejercida por el colonialismo, se sustenta no sólo en un interés por el sujeto indígena, sino también en una preocupación por problematizar otras subjetividades que se encuentran en tensión subalterna frente a los poderes hegemónicos, por ejemplo, el sujeto campesino, el sujeto revolucionario y el sujeto poeta. Este último, aparece de la siguiente manera: "El poeta se quejaba en una silla,/ muy cubierto por el polvo de las bombas,/ contemplándonos perdido y sin hablar./ [...] Lo miramos y le dimos en la madre/ bajo un sol que rajaba las arenas/ justo frente a las huacas de Chan Chan.” (2014:28).

\footnotetext{
${ }^{5}$ Las mayúsculas pertenecen al original.
} 
En una entrevista concedida al poeta Leonardo Sanhueza, Jaime Huenún señala lo siguiente:

La poesía en algunos casos es una demencia controlada e inevitablemente crea imaginarios extraños, espacios y geografías ficticias e insólitas, aunque se refiera a lugares, personajes y sucesos verificables. De este modo la poesía altera el sentido de la realidad, droga al lector con variados, largos o cortos viajes mentales y emocionales. La paradoja es que dichos viajes intensifican una comprensión inusual del mundo, comprensión que no necesariamente es alienante. En ese entendido, de vez en cuando me interesa fundar ciertos territorios, ciertos laberintos situados en el lenguaje que pueden ser puertos, ciudades o pueblos sin existencia en los mapas conocidos. Tal vez el afán sea instaurar vagos poblados, espurias patrias en las cuales perder el nombre, la identidad, las miserias y los hábitos comunes. (Huenún en línea, las cursivas son mías.) $)^{6}$.

Es así como los sujetos poéticos de sus textos se sitúan de forma conflictuada en los espacios que habitan, en su mayoría esos espacios refieren o son la metáfora de lugares o ciudades como Osorno, ya que, precisamente, este tipo de localidad es un producto de la colonización y la reducción ${ }^{7}$, y representa, en su poesía, una crítica a lo que el mismo autor refiere en la cita anterior: las "espurias patrias": "Venganza de la tierra, venganza de las aguas solas/ en los pálidos días de Trumao./ El tren que marcha hasta Osorno/ venciendo las embarcaciones,/ los vaporcitos de Quilmahue y Bellavista/ que ahora navegan en la tierra/ guiados por las ratas/ y las frías lágrimas de la Cruz del Sur." (2012: 134). Así también, cantinas o sectores rurales cercanos a esta ciudad, son representados como espacios que generan un repliegue para los sujetos poéticos de Huenún frente a la experiencia topofóbica que simbolizan ciudades como Osorno: "Los bares mexicanos de Avenida República/ ha tiempo nos parieron: el "Richmond", el/

\footnotetext{
${ }^{6}$ Revisar bibliografía.

7 El término "reducción" alude al emplazamiento de grupos indígenas para su sometimiento al Catolicismo desde la llegada del español a nuestro continente. En Chile, el término comenzó a utilizarse debido a la expropiación de tierras desde el tiempo de la Conquista. Existían en aquel entonces las llamadas "Bulas intercaeteras", documentos jurídicos y eclesiásticos de la corona española que determinaban la supuesta autoridad para disponer de las nuevas tierras conquistadas. Así, el espacio territorial de los mapuche comenzó a "reducirse" como una forma de dar pie a la expansión del imperio español y consecuente dominio de toda cultura indígena. Ocupo el término como una metáfora de lo que se establece en uno de los poemarios de Huenún que tiene precisamente esa palabra como título y en el cual intenta, entre otras cosas, resignificar los espacios "otros" que son reducidos al margen. Es posible encontrar una pormenorizada revisión acerca de este tema desde la perspectiva de una serie de historiadores mapuche, en el libro ; ...Escucha Winka...! Cuatro ensayos de Historia Nacional Mapuche y un epílogo sobre el futuro (2006).
} 
"Niza", la concha del alcohol/ -que divide los cielos/ -que divide la pesca/ -que divide las sombras en la calle mojada" (147).

En la escritura de Jaime Huenún se plantea la complejidad de sujetos intersticiales que se mueven dentro de imaginarios y realidades marginales que dan cabida a su subjetividad y les otorga una mirada crítica sobre su condición subalterna. Se trata de una poética que se sustenta en la importancia del espacio como construcción de experiencia y memoria: "La noche llegó desde un poema de Trakl/ que ella guardaba en la memoria./ Alzamos nuestras copas y, sin prisa,/ cada cual volvió a su propia/ y cotidiana decadencia." (2001: 19). El espacio que se percibe en la poesía de Huenún, es un espacio que recrea simbólicamente el sur: “Así vuelven las empleaditas al Sur Profundo,/ con un hijo natural pegado al pezón de un puerto/ del que jamás podrá partir.” (37); "Las tumbas son llevadas/ al cauce por la nieve/ mientras las becacinas/ graznan indiferentes/ desde un desierto sur [...]" (2016: 119). En ese escenario poético concebido como "suralidad", es posible presenciar una serie de imaginarios espaciales traslapados por estas "espurias patrias", las cuales permiten entender la manera en que subjetividades como la del sujeto mapuche-huilliche conviven en un entorno marcado por la colonialidad.

\section{Imaginarios espaciales del sur en la poética de Ivonne Coñuecar.}

Por otro lado, y proveniente de una zona mucho más austral que la del poeta Huenún -asunto que marcará de manera importante su escritura-, Ivonne Coñuecar construye una poética que, en gran parte, se relaciona con la referencialidad a espacialidades del sur como la Patagonia y a la problematización de la subjetividad manifiesta en la tensión entre experiencia y cuerpo: "allá la gente desaparece/ la Patagonia es gigante y se incendia/ y todos en la caída piensan en salvación/ siguen y siguen desapareciendo/ una lista con nombres, historias en los epitafios" (2014: 134) ${ }^{8}$. La Patagonia se presenta a través de imaginarios provenientes de discursos dominantes como el de la dictadura militar, en ella, el cuerpo interviene como un sólo por citar un ejemplo.

Coñuecar da énfasis a un sujeto poético que aborda el extrañamiento del cuerpo a partir de geografías del sur trastocadas por la imposición del poder:

\footnotetext{
${ }^{8}$ Al igual que en el caso de Huenún, se trabajará con diferentes poemarios de la autora, y las citas de los versos se distinguirán por el año de publicación que se referencia en cada una de ellas.
} 
¿Quién podrá borrar estas cicatrices de cuerpos rotos?/ la culpa para los confesionarios/ nos tenemos en el averno la piel pegoteada/ verano noventa y cuatro Coyhaiqueer/ cavando nuestras pieles como perro buscando huesos/ conocimos la luz y las manos que nos abrieron. Miramos la infancia/ laberinto./ nosotras cruzamos los telones y arruinamos la función (2014: 119).

En relación a la representación del cuerpo en la poesía huilliche, Noemí Sancho señala que éste es simbolizado como un "microespacio donde se intuyen las estructuras sociales, y así también, las representaciones y símbolos del territorio.” (2012: 44). Este tipo de poesía, en el que el cuerpo se manifiesta como espacio político frente al imaginario patagónico, se traduce en Coñuecar a partir de textos como Catabática (2008), Adiabática (2009), Patriagonia (2014), -una trilogía que reúne los dos primeros poemarios más un tercero titulado Anabática-; y por último, Trasandina (2017). Chagas (2010) es otro de sus poemarios; si bien no guarda relación con la Patagonia, éste plantea, desde un sentido más amplio en términos de geografías del sur, una metáfora de Chile y Latinoamérica a partir del cuerpo y la enfermedad. Recientemente también publicó la novela titulada Coyhaiqueer (2018), la cual desarrolla una historia situada entre los años ochenta y noventa en las ciudades de Coyhaique, Valdivia y Santiago.

Desde una arista espacial, la autora prefigura un trazado cartográfico en el que la subjetividad, vista como cuerpo y experiencia, es el elemento en el que se construye una identidad ambigua y en desplazamiento de una sujeto conflictuada por la geografía y la memoria:
Patagonia en el frío que duele
abre su boca el viento y ruge
tiembla en la madera la memoria
silbidos en la chimenea
la noche azul tirita en los labios
que no me abren su escarcha
agujas en el viento blanco / Coyhaique silencio
la anacrónica razón de luto sin testigos
tempestades apagan mis velas / arrastran el polvo de las tumbas
silban en las grietas de mi piel
se calman en mi cansancio catártico / antártico [... $]^{9}$ (2014:22).

En esa dinámica escritural, la sujeto de Coñuecar reside en una memoria de la experiencia que se va configurando entre una poética de los vientos (catabáticos,

\footnotetext{
${ }^{9}$ Se ha respetado, en los versos citados, el uso de barras por parte de la autora.
} 
anabáticos y adiabáticos), y una geografía patagónica. Esta estrategia poética tiene como resultado una experiencia contradictoria entre subjetividad y entorno espacial, siendo esta contradicción, el lugar desde el cual habla la sujeto: "yo te buscaba Patagonia agonía [...] y desde mí / catabática/ malgasto ideas / trazo itinerarios de mi vendabal predilecto/ Coyhaique qué / Coyhaique eco/ viento desgarbado/ costras de eterno invierno" (40).

A diferencia de Huenún, la poesía de Ivonne Coñuecar adquiere un carácter mucho más íntimo y "biográfico", el que le permite a la sujeto poética profundizar y reconstruir una memoria colectiva y también individual, la que va y vuelve por espacios patagónicos que se encuentran en tensión con esa sujeto: "camino en el fascismo de mi Coyhaiqueer/ el silencio telúrico de la gente que saluda por costumbre/ o apellido." (120). Tal como lo afirman Sergio Mansilla (2015) y Fernanda Moraga-García (2017), la escritura de Coñuecar es una poética del desarraigo en la que el desplazamiento de su "yo" lírica en los intersticios de la memoria y el espacio patagónico, da cuenta del carácter represor del modelo neoliberal. Este modelo derivó de la dictadura militar en los años 70 y 80 del siglo pasado, hasta la "política de los acuerdos" (Moulian 1997) pactada por los partidos de izquierda en el período postdictadura, asunto que ha significado el devenir de un Chile trastocado por políticas de consenso que avalaron y legitiman, aún hoy, la Constitución dictatorial de 1980, reproduciendo un sistema amparado en la pérdida de la democracia.

En esta poética, en la que la sujeto realiza un ejercicio nomádico de la memoria, entre un espacio y otro (la Patagonia, Coyhaique, Valdivia, Santiago), Coñuecar convoca a los lectores y lectoras a una propuesta crítica, la que se sitúa en imaginarios disidentes que intentan desmitificar la Patagonia: “[...] no temo a las calles de Coyhaiqueer./ una boca gigante nos traga con su lengua moralista e hipócrita/ que dijeron tanto no y sí y luego no existían las mentiras." (113). Esta propuesta crítica problematiza constantemente los imaginarios-sur, sobre todo los que se relacionan con la mitificación de la Patagonia. Se trata de una poética que no sólo advierte de la Trapananda ${ }^{10}$ comprendida como territorio colonizado, sino que también manifiesta que

\footnotetext{
${ }^{10}$ Es posible entender el término y sus orígenes a partir de lo que nos señala Sergio Mansilla: "Popularmente Aysén se conoce también como Trapananda, nombre que alude a una tierra misteriosa, encantada, lejana, inhóspita, fabulosa; se asocia también con la Ciudad de los Césares. Más allá de un cierto origen del nombre vinculado con crónicas de viajes de los tiempos de la conquista, no está del todo claro por qué a la Región de Aysén sus propios habitantes la denominan Trapananda, aunque a primera vista resulta obvio que el nombre funciona como marca de diferencia identitaria." (2015: 165).
} 
esta misma colonización impone sus límites y trazos cartográficos en la geografía del cuerpo, convirtiéndolo en un "cuerpo de la precariedad” (Moraga-García 2012).

Desde ese enfoque, por ejemplo, la sujeto poética de Coñuecar, a partir de su condición lésbica, se sitúa como un "cuerpo de la precariedad" en los pliegues o intersticios de los imaginarios patagónicos de aquella colonización: “[...] los espejos y los incendios/ y el viento sube como explosión/ no dejan salir a la niña bomba personal/ que grita revolución para sus adentros/ mientras sigue amarrada dentro de un clóset." (146). Desde una perspectiva de género, ella se desplaza entre estos imaginarios para confrontarse a los "discursos heteronormativos" (Guerra 2012) que los producen.

La voz poética de Coñuecar es una con el espacio patagónico, es la metáfora de un cuerpo degradado que ha sido colonizado y arrasado a partir de un esquema mítico que se traduce en los imaginarios gauchescos y exóticos con que se instala a Coyhaique y a la Patagonia en el discurso colonialista: "me he quedado sin país, vasto territorio sin país/ es la imaginaria certeza de la Patagonia,/ de la willimapu, de mi newen extirpado,/[...] nos observaban como reality show/ había tantas banderas, himnos y colores/[...] la arteria latinoamericana haciendo erupción [...]” (2017:30). A su vez, el pasado, la adolescencia, el territorio, el cuerpo y la experiencia, son los elementos determinantes de una poesía que constituye la búsqueda de la emancipación de la subjetividad: "en mi cuerpo se escribe un mapa/ desde lo cotidiano me hace viajar/ reúno los años para mirarme en el espejo/ a esa sola niña sola/ a esa perpleja adolescente atómica [...]” (24). En esa dinámica poética, la sujeto es afectada por los cambios físicos del espacio que la rodea; Coyhaique o "Coyhaiqueer" son formas especulares de verse a sí misma frente a la memoria.

\section{De espacialidades topolésbicas y espurias patrias.}

Como se ha evidenciado, las producciones poéticas de Jaime Huenún e Ivonne Coñuecar asumen formas discursivas que critican las problemáticas sobre los imaginarios espaciales del sur como resultado de una relación conflictiva entre espacio y experiencia. En el caso de Huenún, estas problemáticas se manifiestan en la presencia de un sujeto poético inmerso muchas veces en espacios topofóbicos desde los cuales se desprende la idea de espurias patrias, es decir, territorios del sur retratados como signos de violencia que oprimen a ese sujeto. Por ejemplo, en sus libros Ceremonias y Reducciones, es clara la referencia de las reducciones territoriales a las que ha sido sometida la sociedad mapuche: "la ciudad viene hasta ti con sus ácidas cadenas/ y esas 
grúas que levantan los cimientos de la historia./ Son nublados palacetes donde anidan pardos búhos/ y la opaca lluvia andina de la ténue Cruz del Sur.” (2014:50). En sus libros Puerto Trakl y Fanon City Meu, el poeta elabora espacios ficticios en relación a espacialidades que comprenden el sur de Chile y de Latinoamérica, para generar una metáfora de la violencia que ha enfrentado no sólo la nación mapuche, sino también otras sociedades indígenas latinoamericanas.

Por otro lado, es posible plantear que en el caso de Ivonne Coñuecar, gran parte de su escritura se pregunta sobre la experiencia problemática de una sujeto poética lesbiana que se desplaza por espacios del sur heteronormados, como lo es la Patagonia. Espacios que sus poemarios van resignificando de manera insubordinada, generando así una poética espacial topolésbica: “[...] vuelven las calles de Coyhaique/ a escarchar mis pasos / delitos bajo cero/ mi cordillera carcelaria/ sin derecho a réplica en el trance telúrico/ canto porque no sé cantar/ el amor son las ciudades que he habitado/ y he estado muerta en las fronteras de la piel" (2014:26). Esta problemática identitaria se traduce en todos sus poemarios, pues en ellos “[...] la sujeto impugna la lógica de dominación corporal-territorial y señala, por otro, el espacio de una identidad lésbica, cuestionando implícitamente la tramposa dicotomía de las diferencias.” (Moraga-García 2012).

En ambos poetas, la triada imaginarios/espacio/experiencia se manifiesta a partir de notorias problemáticas, las que coinciden con la idea de la argentina María Lucía Puppo cuando señala la relación de la poesía con el espacio: “[...] la pregunta por el espacio en poesía no tiene que ver con un afán métrico, mimético o totalizador, sino con el acto de restituir una experiencia, de devolverle al espacio su contexto vital, simbólico y afectivo." (2013:11). Desde esa premisa, la problemática que se instala en las producciones poéticas de los dos autores da cuenta de imaginarios espaciales del sur que, en el caso de Huenún, se despliegan en la representación topofóbica de espurias patrias, y desde la perspectiva de Coñuecar, mediante espacialidades topolésbicas.

En base a lo anterior, es posible asumir que las subjetividades se sumergen y se entregan en una invención permanente de sus propias representaciones, a través de las cuales se construyen identidades, fenómeno que precisamente es el que se representa en las poéticas de nuestros autores. Estas representaciones, inventadas y elaboradas con materiales apropiados del capital simbólico social, tienen una influencia sobre las subjetividades y los comportamientos sociales en espacios determinados, por ejemplo, en las "espurias patrias" que configura Huenún, o en las espacialidades topolésbicas en 
Patriagonia y Trasandina de Coñuecar. En esos imaginarios espaciales del sur, las dinámicas de poder se rodean de símbolos que las legitiman y engrandecen. En relación a esto último, Bronislaw Baczko en su libro Los imaginarios sociales. Memorias y esperanzas colectivas (1999) señala lo siguiente:

El dispositivo imaginario asegura a un grupo social un esquema colectivo de interpretación de las experiencias individuales tan complejas como variadas, la codificación de expectativas y esperanzas así como la fusión, en el crisol de una memoria colectiva, de los recuerdos y de las representaciones del pasado cercano o lejano. La potencia unificadora de los imaginarios sociales está asegurada por la fusión entre verdad y normatividad, informaciones y valores, que se opera por y en el simbolismo. (30).

Siguiendo la idea de la cita, es posible entender los imaginarios espaciales del sur en la poesía de Jaime Huenún e Ivonne Coñuecar como "dispositivos" de significación colectiva, en los que es posible interpretar las experiencias del sujeto subalterno. Esta interpretación se concreta mediante los intersticios que las voces poéticas despliegan y repliegan en sus discursos.

La poesía de Huenún y Coñuecar asume una condición simbólica que manifiesta la posibilidad de evidenciar la relación conflictiva entre subjetividad y espacio, considerado este último como un aspecto político no sólo atribuido al territorio, sino como parte indisociable del sujeto y su experiencia. En ese sentido, estas poéticas también permiten entender al cuerpo como espacio desde el cual se construyen imaginarios decolonizadores.

Por otro lado, la poesía de Huenún y Coñuecar se inserta en la literatura nacional como un flujo discursivo que reconstruye, desde una posición política y estética, determinados elementos simbólicos que entran en tensión con lo social, sobre todo en torno al espacio entendido como un receptáculo de fuerzas de poder en que la experiencia de un/a sujeto se ve condicionada. Así, la escritura de estos autores puede ser entendida como un espacio simbólico que genera, desde su propio discurso poético, espacios "otros" o heterotopías (Foucault 1994) dentro del campo cultural (Bourdieu 1966) y literario nacional, otorgándole un valor de resistencia política a su propia escritura.

Se trata de una poesía que da cuenta no sólo de una problemática alusiva a los desplazamientos y segregaciones territoriales, como las reducciones (en el caso de Huenún), sino también está orientada a evidenciar la trama de elementos que inciden en 
la configuración de identidades que se encuentran en fricción con la "comunidad imaginada" (Anderson 1983) de la nación chilena. Es decir, identidades que se enfrentan a una construcción ideológica homogeneizante que las margina del constructo social, pues en ellas no ve el beneficio para el progreso o desarrollo de un proyecto económico nacional liderado por las políticas neoliberales de los gobiernos de la postdictadura.

\section{Conclusiones provisorias.}

En relación al análisis propuesto, cabe señalar que su intención está en la posibilidad de indagar sobre un aspecto específico en estos dos autores: las espacialidades del sur como construcción imaginaria, asunto que contribuye a la apertura de nuevas interrogantes y reflexiones sobre poéticas que se instalan en el campo literario nacional desde una posición no sólo estética, sino también política en cuanto a la relación espacio-experiencia.

De lo anterior, es posible establecer que someter a análisis la poesía de Huenún y Coñuecar es una labor ineludible dentro del campo de la literatura chilena actual, porque se trata de valorar un corpus poético que critica las diferentes estrategias de colonización como son la identidad, la raza, el género, entre otras.

En la producción de estos autores existe, como ya hemos visto, una propuesta que elabora, de diversas formas, una poética de los imaginarios espaciales del sur. A través de la conformación del espacio-sur, el/la sujeto que se evidencia en los poemas revisados, es el resultado de una trama simbólica articulada por la experiencia, y tal como menciona Maribel Mora Curriao:

En el mayor de los casos esta poesía se escribe desde los límites que hacen visible lo 'uno' frente a un 'otro' que les niega contemporaneidad. Lo ausente se hace presente en el discurso poético tensionando la historia que se pretende releer $\mathrm{y}$ reescribir. Lo uno y lo otro en una dialéctica que puede resultar autodestructiva, pero que ha significado una posibilidad de autonomía simbólica frente a una realidad social, política y culturalmente compleja. (2013: 49).

Estas escrituras pueden movilizar una serie de elementos reflexivos en torno a lo espacial/territorial, lo político y lo experiencial, transformándose también en herramientas de subversión frente a discursos provenientes de la colonialidad o amparados bajo construcciones falogocéntricas, que también forman parte de la 
colonización. Pero además, son una lectura a contrapelo de la dimensión simbólica con que se han configurado los discursos oficiales.

A partir de todo lo expuesto, creemos que el presente análisis puede ser un material crítico de contribución a los estudios sobre la poesía de ambos poetas y de la poesía mapuche actual, ya que aún no existen trabajos comparativos entre ambas propuestas artísticas que las exploren a través de la articulación entre las nociones de imaginario, espacio y experiencia.

Finalmente, se espera que esta propuesta investigativa pueda ser un aporte a nuevas entradas de análisis para la poesía de ambos autores, y de esta misma manera se convierta no en una lectura acabada, sino una que posibilite el interés para otras formulaciones académicas en el contexto de la poética mapuche actual.

\section{Bibliografías}

Anderson, Benedict. Comunidades imaginadas. Reflexiones sobre el origen y la difusión del nacionalismo. México D. F: Fondo de Cultura Económica S.A., 1993.

Arellano, Claudia y Riedemann, Clemente. Suralidad. Antropología Poética del Sur de Chile. Valdivia, Puerto Varas, Chile: Suralidad Ediciones y Ediciones Kultrún, 2012.

Baczko, Bronislaw. Los imaginarios sociales. Memorias y esperanzas colectivas. Buenos Aires; Argentina: Ediciones Nueva Visión, 1999.

Bhabha, Homi. El lugar de la cultura. Buenos Aires, Argentina: Ediciones Manantial, 1994.

Bourdieu, Pierre. Capital cultural, escuela y espacio social. Madrid: Siglo Veintiuno Editores, 1997.

Canales, Pedro. Zuamgenolu: Pueblo mapuche en Contexto de Estado Nacional Chileno, siglos XIX - XXI. Santiago, Chile: Ediciones Usach, 2016.

Cárcamo-Huechante, Luis. Tramas del Mercado: Imaginación económica, cultura pública y literatura en el Chile de fines del siglo XX. Santiago, Chile: Cuarto Propio, 2007.

Castoriadis, Cornelius. Figuras de lo pensable. México D.F: Fondo de Cultura Económica, 2006.

Coñuecar, Ivonne. Chagas. Santiago, Chile: Editorial Fuga, 2010.

Coñuecar, Ivonne. Patriagonia: Catabática, Adiabática, Anabática. Santiago, Chile: Lom Ediciones, 2014.

Coñuecar, Ivonne. Trasandina. Coyhaique, Chile: Ñire Negro Ediciones, 2017.

Coñuecar, Ivonne. Coyhaiqueer. Chile: Ñire Negro Ediciones, 2018.

Foucault, Michel. El cuerpo utópico. Las Heterotopías. Buenos Aires, Argentina: Nueva Visión, 2010.

Guerra, Lucía. "Subjetividades lesbianas en los espacios no inscritos de la identidad.". Revista Aisthesis 50 (2012): 157-171.

Huenún, Jaime. Ceremonias. Santiago, Chile: Editorial de la Universidad de Santiago de Chile, 1999.

Huenún, Jaime. Puerto Trakl. Santiago, Chile: Lom Ediciones, 2002. 
Huenún, Jaime. Epu Mari Ülkantufe ta fachantü. 20 Poetas Mapuche Contemporáneos. Santiago, Chile: Lom Ediciones, 2003.

Huenún, Jaime. La memoria iluminada: Poesía Mapuche Contemporánea. España: Maremoto, 2007.

Huenún, Jaime. Los cantos ocultos. Antología de poesía indígena latinoamericana. Santiago, Chile: Lom Ediciones, 2008.

Huenún, Jaime. Reducciones. Santiago, Chile: Lom Ediciones, 2012.

Huenún, Jaime. Fanon City Meu. Santiago, Chile: Das Kapital Ediciones, 2014.

Huenún, Jaime. La calle Mandelstam y otros territorios apócrifos. Santiago, Chile: Fondo de Cultura Económica, 2016.

Laplantine, Francois y Nouss, Alexis. Mestizajes. De Arcimboldo a zombi. Buenos Aires, Argentina: Fondo de Cultura Económica, 2007.

Mansilla, Sergio. “'Adiabática yo': memoria, nomadías y localizaciones en la poesía de Aysén (en torno a la escritura de Ivonne Coñuecar).". Afpunmapu, fronteras, borderlands. Poética de los confines: Chile-México. Eds. Tatiana Calderón Le Joliff y Edith Mora Ordóñez. Valparaíso, Chile: Ediciones Universitarias de Valparaíso. 2015, 147-169.

Mansilla, Sergio. "Los archivos de la niebla: En torno a Reducciones de Jaime Huenún Villa.". Revista Alpha 40 (2015): 149-164.

Marimán, Pablo, Caniuqueo Huircapán, Sergio, Millalén Paillal, José y Levil Chicahual, Rodrigo. i...Escucha, Winka...! Cuatro ensayos de Historia nacional Mapuche y un epílogo sobre el futuro. Santiago, Chile: Lom Ediciones, 2006.

Mora Curriao, Maribel. "Poesía mapuche: la instalación de una mismidad étnica en la literatura chilena.". Revista A contra corriente 3 (2013): 21-53.

Moraga-García, Fernanda. "Catabática: cartografías de subjetividades fronterizas." Revista Literatura y Lingüística 26 (2012): 47-59.

Moraga-García, Fernanda. "La ciudad a puerta cerrada: La Patriagonia de Ivonne Coñuecar.". Milena Rodríguez. Casa en que nunca he sido extraña. Las poetas hispanoamericanas: identidades, feminismos, poéticas (Siglos XIX-XXI). New York: Peter Lang, 2017.

Moulian, Tomás. Chile actual: Anatomía de un mito. Santiago, Chile: Lom Ediciones, 1997.

Nahuelpán, Héctor, Huincan Piutrin, Herson y Marimán, Pablo. Ta Iñ Fijke Rakizuameluwün. Historia, colonialismo y resistencia desde el país mapuche. Temuco; Chile: Ediciones Comunidad de Historia Mapuche, 2012.

Park, James. "Contextos, textos y paratextos de Jaime Luis Huenún Villa". Revista Alpha 17 (2010): 9-17.

Puppo, María Lucía. Entre el vértigo y la ruina: poesía contemporánea y experiencia urbana. Buenos Aires, Argentina: Biblos, 2013.

Sancho, Noemí. Cartografía poética: Representaciones del territorio en la poesía de tres poetas wuilliche (1999-2012). Tesis Doctoral. Pontificia Universidad Católica de Chile. Chile, 2018.

Sanhueza, Leonardo. "La poesía en algunos casos es una demencia controlada". Entrevista a Jaime Huenún. http://www.lun.com/Pages/frmPrintNews.aspx?ItemID=\%20291368\&NewsTyp $\mathrm{e}=$ Search $\& \mathrm{SF}=1 \&$ SupplementId $=0$

Stavrides, Stavros. Hacia la ciudad de umbrales. España: Editorial Akal, 2016. 